\title{
ANALISA KERUSAKAN LAPIS PERKERASAN LENTUR JALAN MENGGUNAKAN METODE PAVEMENT CONDITION INDEX (PCI)
}

\author{
(Study Kasus: Jalan Dusun Batu Alang, Sumbawa)
}

\author{
Rima Devira Azhari ${ }^{1}$, Hermansyah ${ }^{2}$, Eti Kurniati ${ }^{3}$ \\ Program Studi Teknik Sipil, Fakultas Teknik Universitas Teknologi Sumbawa, Sumbawa ${ }^{123}$
}

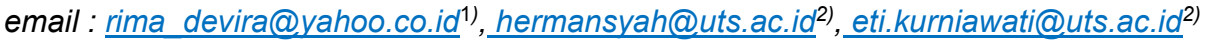

\begin{abstract}
Abstrak
Kota Sumbawa Besar merupakan ibukota dari Kabupaten Sumbawa, Nusa Tenggara Barat. Dari luasnya Sumbawa besar yang sampai dengan $6.644 \mathrm{~km}^{2}$, jalan yang ada di Sumbawa Besar ini kemungkinan sebagian memiliki kerusakan. Khususnya pada daerah Batu alang sampai dengan Universitas Teknologi Sumbawa dengan jarak panjang 2200m dengan lebar jalan $3 \mathrm{~m}$ dan tiap segmen memiliki 100m/segmen. Jalan tersebut sering dilalui oleh kendaraan baik kendaraan ringan ataupun sedang. Sehingga mengakibatkan terjadinya kerusakan pada jalan tersebut dan memerlukan pemeliharaan dan perbaikan. Maka dari peneliti bertujuan untuk mengidentifikasikan kerusakan jalan dan memberikan solusi perbaikan jalan. Metode yang digunakan adalah metode Pavement Condition Index dengan segmen 22 pada ukuran 100m/segmen. Berdasarkan perhitungan diperoleh jenis kerusakan dengan metode Pavement Condition Index dari banyaknya jenis kerusakan jalan. Adapun kerusakan yang paling parah yaitu kerusakan fair dengan nilai $\mathrm{PCl} 21$ dan kerusakan yang tidak ada kerusakan yaitu kerusakan excellent dengan nilai 100.
\end{abstract}

Kata Kunci :

Jenis Kerusakan, Pemeliharaan, Pavement Condition Index.

\section{PENDAHULUAN}

\section{LATAR BELAKANG}

Setiap prasarana yang pengemudi lewati, pengemudi mengharapkan kondisi jalan tersebut sangat baik sehingga pengemudi mudah melewati dengan nyaman. Pada umumnya pengemudi akan menghindari jalanan yang rusak ataupun retak. Kondisi ini merupakan permasalahan masyarakat umum pengguna jalan. Jika kerusakan jalan disebabkan oleh lapisan tanah dasar maka harus diketahui karakteristik dari tanah dasar tersebut.

Jalan merupakan prasarana transportasi darat yang sering digunakan oleh masyarat sebagai penghubung tempat antara tempat satu ke tempat lainnya. Kondisi jalan berpengaruh untuk mempercepat kelancaran mobilisasi barang atau jasa secara aman dan jasa. Namun seiring berjalannya waktu, penduduk semakin padat sehingga menyebabkan pengendara pada jalanan tersebut tidak terkendali dan berpengaruh pada volume lalu lintas semakin tinggi. Jalan yang terbebani dengan volume lalu lintas yang melebihi kapasitas mempengaruhi kualitas mutu pada jalan sehingga terjadinya kerusakan pada jalan.

Perkerasan jalan memiliki beberapa bagian lapisan yaitu lapisan tanah dasar, lapisan pondasi bawah dan lapisan pondasi atas. Pekerasan jalan yang baik dapat memberikan kenyamanan, keamanan, dan kelancaran bagi pengendara. Dalam perencanaan pekerasan jalan harus mengetahui faktor - faktor penyebab kerusakan jalan tersebut. Ada beberapa hal yang menyebabkan kerusakan jalan yaitu sifat tanah dasar dan beban lalu lintas. Hal itu dapat mempengaruhi kondisi jalan. Lapisan perkerasan sering mengalami kerusakan atau kegagalan sebelum mencapai umur rencana. Ada dua hal yang dapat mengetahui kerusakan perkerasan jalan yaitu kegagalan fungsional dan kegagalan struktur. Kota Sumbawa Besar merupakan ibukota dari Kabupaten Sumbawa, Nusa Tenggara Barat. Dari luasnya Sumbawa besar yang sampai dengan $6.644 \mathrm{~km}^{2}$, jalan yang ada di Sumbawa Besar ini kemungkinan sebagian memiliki kerusakan. Khususnya pada daerah Batu alang sampai dengan Universitas Teknologi Sumbawa dengan jarak panjang $2200 \mathrm{~m}$. Untuk memenuhi kebutuhan jalan dengan tingkat kualitas tertentu maka diperlukan usaha agar jalan tetap mantap, maka dari itu untuk mengetahui tingkat kerusakan atau kondisi kerusakan jalan tersebut maka peneliti akan melakukan penilaian terhadap kondisi eksisting jalan. Nilai kondisi jalan ini juga akan digunakan untuk menentukan penanganan pada jalan baik dari peningkatan, pemeliharaan berkala, atau bahkan pemeliharaan rutin.

Penilaian untuk mengetahui jenis dan tingkat kerusakan perkerasan jalan dapat dicari dengan metode Pavement Condition Index ( $\mathrm{PCl})$ dan metode perbaikannya. Metode Pavement Condition Index (PCI) merupakan metode yang dapat mengetahui nilai dari kondisi kerusakan perkerasan jalan berdasarkan jenis kerusakan jalan, tingkat kerusakan jalan, dan digunakan sebagai acuan pemeliharaan jalan. 
Dalam penelitian ini akan mencoba melakukan penilaian kondisi perkerasan jalan terlebih dahulu untuk mengetahui jenis-jenis kerusakan jalan, penyebab kerusakan jalan, dan tingkat kerusakan pada perkerasan jalan serta menetapkan nilai kondisi perkerasan jalan. Hal ini dilakukan agar kondisi kerusakan perkerasan jalan tidak semakin parah. Selain itu, untuk mengetahui nilai kondisi ruas jalan pada jalan yang akan di teliti dengan metode Pavement Condition Index (PCl).

Dalam penelitian ini ada beberapa tujuan yang peneliti lakukan untuk tugas akhir ini yaitu mengidentifikasi jenisjenis kerusakan yang terjadi pada ruas jalan Dusun Batu Alang sampai dengan kampus Universitas Teknologi Sumbawa. Dan memberikan solusi perbaikan untuk setiap perkerasan jalan yang rusak.

Dari batasan masalah ini, lokasi yang akan dijadikan studi kasus yaitu ada di Dusun batu alang sampai dengan universitas teknologi Sumbawa. Dengan panjang jalan $2200 \mathrm{~m}$ dan titik segmen $25 \mathrm{~m}$ dengan banyaknya 88 titik segmen. Adapun batasan masalah yang penulis tetapkan. Dari latar belakang dan rumusan masalah untuk membatasi ruang lingkup yang masalah agar tidak menyimpang dari pembahasan yaitu mengidentifikasi jenis-jenis kerusakan jalan yang akan dilakukan pengamatan kondisi jalan secara visual pada struktur perkerasan jalan yang ada di wilayah Dusun Batu Alang sampai dengan kampus Universitas Teknologi Sumbawa. Dan Jenis-jenis kerusakan jalan sesuai dengan data jalan yang didapat dari pengukuran jalan yang ada di Dusun Batu Alang sampai dengan Unversitas Teknoligi Sumbawa.

\section{Rumusan Masalah}

\section{METODE PENELITIAN}

Berdasarkan latar belakang diatas maka perumusan masalah pada tugas akhir ini dapat disusun sebagai berikut yaitu:

1. Bagaimana identifikasi jenis-jenis kerusakan yang terjadi pada ruas jalan Dusun Batu Alang sampai dengan kampus Universitas Teknologi Sumbawa?

2. Bagaimana solusi perbaikan untuk perkerasan jalan yang rusak?

\section{Lokasi Penelitian}

Lokasi penelitian merupakan tempat penelitian dilakukan. Penetapan lokasi penelitian merupakan salah satu yang sangat penting karena dengan ketetapan lokasi penelitian. Tujuan yang sudah ditetapkan akan memudahkan penulis untuk menyusun. Lokasi penelitian ini dilakukan diruas jalan pada Dusun batu alang sampai dengan kampus Universitas Teknologi Sumbawa, Kabupaten Sumbawa Barat. Nusa Tenggara Barat. Dimana kerusakan trsebut tidak sebanding lurus dengan umur rencana. Maka dari itu, penelitian ini dilakukan guna mengetahui identifikasi kerusakan jala pada Dusun Batu Alang, Kabupaten Sumbawa, Nusa Tenggara Barat.

Penelitian ini akan dilakukan secara langsung tepatnya distudi lapangan tersebut dan pengambilan data direncanakan selama kurang lebih 2 minggu guna untuk mengidentifikasi jenis dan tingkat kerusakan yang terjadi, yang dimulai dari Dusun Batu Alang sampai dengan kampus Universitas Teknologi Sumbawa, Kabupaten Sumbawa, Nusa Tenggara Barat.

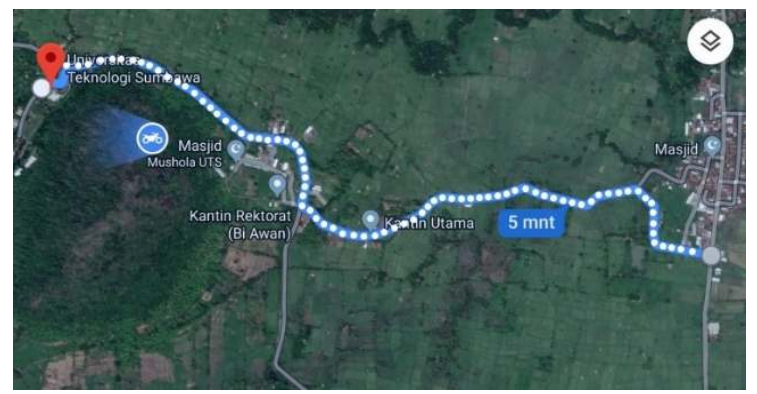

\section{Gambar 3.1 Lokasi Penelitian (Sumber: Google Map)}

\section{Metode Penelitian}

Metode yang digunakan di dalam penelitian ini adalah metode Pavement Condition Index (PCl). Dalam melakukan metode ini, secara umum metodologi pelaksanaan studi kasus ini memiliki beberapa cara yaitu:

1) Analisis gambaran kondisi kerusakan jalan.

2) Analisis faktor penyebab kerusakan jalan dengan metode Pavement Condition Index ( $\mathrm{PCl})$.

3) Solusi perbaikan untuk penanganan kerusakan jalan

\section{Analisis Gambaran Kondisi Kerusakan Jalan}

Pengumpulan data pada ruas jalan Dusun Batu Alang sampai dengan Kampus Universitas Teknologi Sumbawa di Kabupaten Sumbawa Besar dengan panjang jalan $2200 \mathrm{~m}$ yang dilakukan melalui survey kondisi permukaan jalan. Survey dilakukan secara visual yang dibantu dengan peralatan sederhana dengan membagi ruas jalan sampai dengan 22 segmen dengan ukuran $100 \mathrm{~m}$ persegmen. 


\section{Bagan Alur Penelitian}

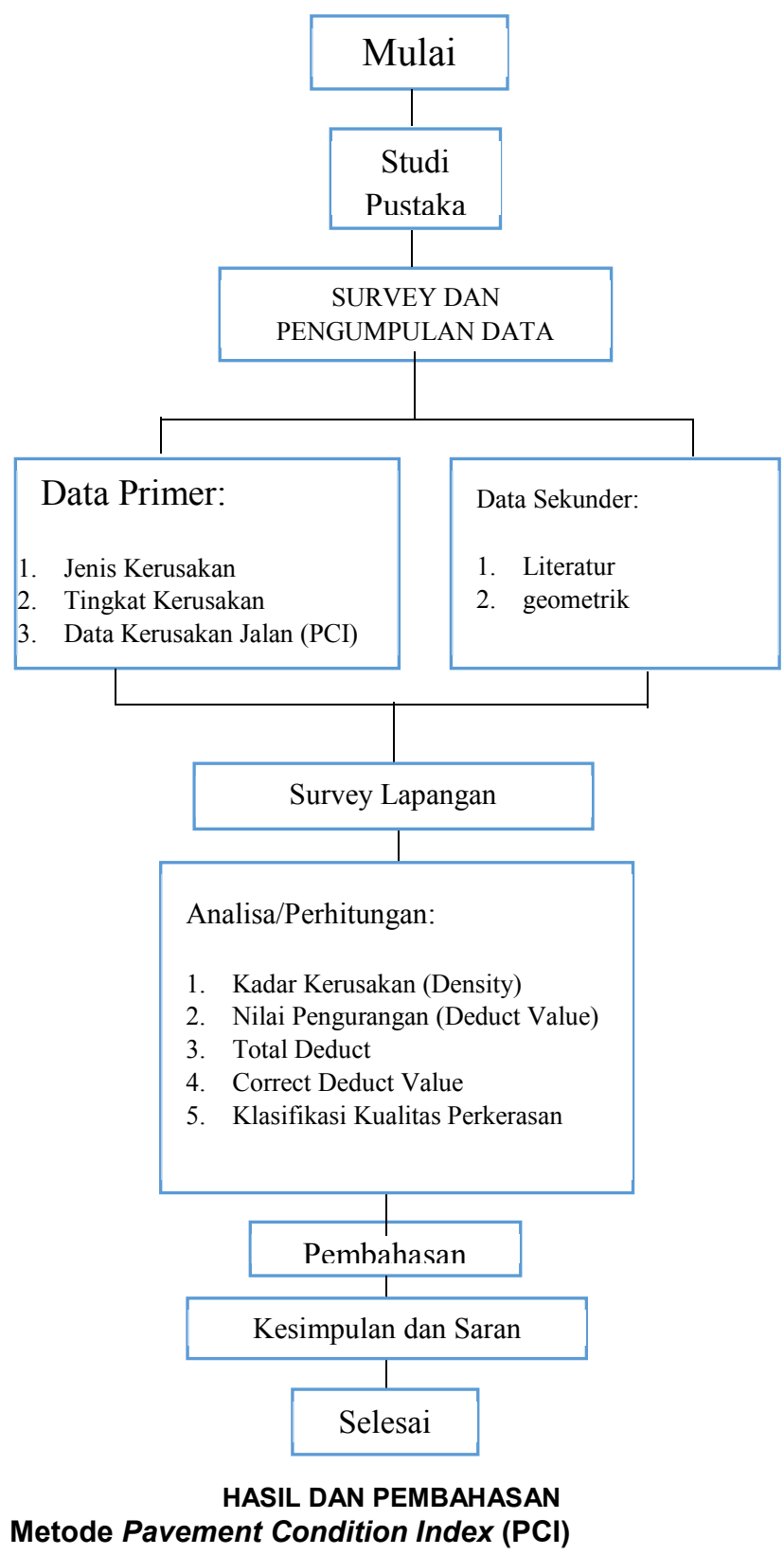

Sulaksono (2001) mengatakan bahwa pada dasarnya setiap struktur perkerasan jalan akan mengalami proses pengrusakan secara progresif sejak jalan pertama kali dibuka untuk lalu lintas. Untuk mengatasi hal tersebut, maka diperlukan metode Pavement Condition Index (PCl) agar dapat disusun program pemeliharaan jalan yang akan dilakukan.

\section{Pengertian Metode Pavement Condition Index (PCI)}

Pavement Condition Index (PCI) merupakan metode yang digunakan untuk menentukan tingkat/nilai kondisi permukaan perkerasan jalan yang ditinjau dari segi fungsional yang mengacu pada kondisi kerusakan dipermukaan perkerasan yang terjadi. Pavement Condition Index $(\mathrm{PCl})$ memiliki nilai index numerik. Nilai tersebut diantara 0 (nol) yang menunjukan kondisi jalan yang sangat buruk sampai dengan nilai 100 (seratus) yang menunjukan kondisi angka sempurna. $\mathrm{PCl}$ ini didapankan dari hasil survei visual. Kerusakan tersebut dapat dinilai saat survei lapangan dari tingkat kerusakan, tipe kerusakan, dan ukurannya yang diidentifikasikan saat survei lapangan. Pavement Condition Index $(\mathrm{PCl})$ adalah salah satu sistem penilaian kondisi perkerasan jalan berdasarkan jenis, tingkat kerusakan yang terjadi dan dapat digunakan sebagai acuan dalam usaha pemeliharaan.

Informasi kerusakan yang diperoleh sebagai bagian dari survei kondisi Pavement Condition Index (PCI), memberikan informasi sebab akibat dari kerusakan perkerasan jalan tersebut.

Dalam metode Pavemnet Condition Index (PCl), untuk mengevaluasi tingkat kerusakan jalan tersebut ada tiga hal yang diperlukan:
1) Tipe Kerusakan
2) Tingkat Keparahan Kerusakan
3) Jumlah Atau Kerapatan Kerusakan

Metode Pavement Condition Index (PCI) dapat memberikan informasi hanya saat pelaksanaan survei lapangan dilakukan, tetapi tidak dapat memberikan prediksi dimasa yang akan datang. Untuk melakukan penilaian kondisi perkerasan jalan terlebih dahulu ditentukan jenis kerusakan, penyebab, serta tingkat kerusakan yang terjadi.

\section{Penilaian Menggunakan Metode PCI}

Menurut Shahin (1994) kondisi perkerasan jalan digolongkan menjadi beberapa tingkatan kondisi jalan, yaitu akan dijelaskan pada Tabel 1 .

Tabel 1. Hubungan Nilai PCI dengan Kondisi Jalan
\begin{tabular}{|l|l|}
\hline $\begin{array}{c}\text { Nilai Pavement } \\
\text { Condition Index } \\
\text { (PCI) }\end{array}$ & \multicolumn{1}{|c|}{ Kondisi Jalan } \\
\hline $100-85$ & Sempurna (Exellent) \\
\hline $85-70$ & Sangat Baik (Very Good) \\
\hline $70-55$ & Cukup (Fair) \\
\hline $55-40$ & Jelek (Poor) \\
\hline $40-25$ & Sangat Jelek (Very Poor) \\
\hline $25-10$ & Gagal (Failed) \\
\hline $10-0$ & \\
\hline
\end{tabular}

(Sumber: Hary Christady Hardiyatmo, 2007)

Untuk mengukur kondisi perkerasan jalan, maka dilakukan evaluasi nilai kondisi jalan. Masing - masing kondisi memeiliki jenis kerusakannya baik dari jenis jalan yang sempurna sampai dengan jenis jalan yang gagal. Secara umum kondisi permukaan jalan menurut AASHTO dikelompokkan menjadi 3 , yaitu: 
1. Baik (good), merupakan kondisi perkerasan jalan yang menunjukkan kerusakan/cacat yang membutuhkan pemeliharaan rutin untuk mempertahankan kondisi jalan.

2. Sedang (fair), merupakan kondisi perkerasan jalan yang menunjukkan kerusakan/cacat yang cukup signifikan dan membutuhkan pemeliharaan berkala.

3. Buruk (poor), merupaka kondisi perkerasan jalan yang sudah cukup meluas kerusakannya sehingga jalan tersebut membutuhkan program peningkatan kondisi jalan yang lebih baik lagi.

\section{Perhitungan Pavement Condition Index (PCI)}

Pavement Condition Index (PCl) adalah indeks bernomor diantara 0 untuk kondisi perkerasan yang gagal (failed), dan 100 untuk kondisi perkerasan yang baik sekali. Perhitungan $\mathrm{PCl}$ didasarkan atas hasil survei kondisi jalan secara visual yang teridentifikasi dari tipe kerusakan, tingkat kerusakan (severity), dan kuantitasnya.

\section{Kadar Kerusakan (Density)}

Density atau kadar kerusakan adalah persentase luasan atau panjang total dari suatu jenis kerusakan terhadap luasan suatu unit segmen yang diukur dalam meter persegi atau meter panjang. Nilai kadar kerusakan suatu jenis kerusakan dibedakan juga berdasarkan tingkat kerusakannya. Adapun rumus untuk mencari kadar kerusakan yang ada pada jalan tersebut.

$$
\begin{aligned}
& \text { Density }=\frac{A d}{A s} 100 \% . . \\
& \text { Density }=\frac{L d}{A s} \times 100 \% .
\end{aligned}
$$

Penjelasan:

$A d=$ luas jenis kerusakan untuk tiap tingkat kerusakan $\left(\mathrm{m}^{2}\right)$

Ld = Panjang Total Jenis Kerusakan untuk Tiap Tingkat Kerusakan $\left(\mathrm{m}^{2}\right)$

As = luas total segmen $\left(\mathrm{m}^{2}\right)$

\section{Nilai Pengurangan (Deduct Value)}

Deduct value atau nilai pengurangan adalah nilai pengurangan untuk tiap jenis kerusakan yang diperoleh dari kurva hubungan antara density dan deduct value. yaitu dengan cara memasukan persentase density pada grafik masing-masing jenis kerusakan, kemudian menarik garis vertikal sampai memotong pada tingkat kerusakan (low, medium, dan high) selanjutnya pada perpotong tersebut ditarik garis horizontal dan akan didapat nilai nilai pengurangan.

Density - Deduct Value

\section{Total Deduct Value (TDV)}

Total Deduct Value (TDV) adalah nilai total dari individual deduct value untuk tiap jenis kerusakan dan tingkat kerusakan yang ada pada suatu unit penelitian. Menghitung nilai total pengurangan (total deduct value/TDV) untuk masing-masing unit penelitian. Total Deduct Value (TDV) adalah nilai total dari individual deduct value untuk tiap jenis kerusakan dan tingkat kerusakan yang ada pada suatu unit penelitian.

\section{4. $\quad$ Corrected Deduct Value (CDV)}

Setelah didapat nilai pengurangan kualitas keseluruhan, kemudian mengkoreksi dengan menggunakan gambar koreksi Deduct Value (CDV). Corrected Deduct Value (CDV) diperoleh dari kurva hubungan antara nilai TDV dengan nilai CDV dengan pemilihan lengkung kurva sesuai dengan jumlah nilai individual deduct value yang mempunyai nilai lebih besar dari lima. Menghitung nilai koreksi nilai pengurangan (correccted deduct value/CDV) untuk masing-masing unit penelitian. Corrected Deduct Value (CDV) diperoleh dari kurva hubungan antara nilai TDV dengan nilai CDV dengan pemilihan lengkung kurva sesuai dengan jumlah nilai individual deduct value yang mempunyai nilai lebih besar dari dua.

\section{Klasifikasi Kualitas Perkerasan}

Jika nilai CDV telah diketahui, maka nilai $\mathrm{PCl}$ untuk tiap unit dapat diketahui dengan Menghitung nilai pavement condition index $(\mathrm{PCl})$ untuk masingmasing unit penelitian.

$\mathrm{PCl}(\mathrm{s})=100-\mathrm{CDV}$

Keterangan:

$\mathrm{PCl}_{\mathrm{s}}=\mathrm{PCl}$ untuk setiap unit segmen atau unit penelitian.

CDV $=$ CDV dari setiap unit sampel.

Untuk nilai $\mathrm{PCl}$ secara keseluruhan:

$\mathrm{PCl}=\sum \mathrm{PCI}(\mathbf{s}) / \mathbf{N}$

Keterangan:

$\sum \mathbf{P C I}_{\mathrm{s}}=$ keseluruhan $\mathrm{PCl}$ untuk setiap unit segmen atau unit penelitian.

$\mathrm{N}=$ Jumlah unit sampel

Untuk menentukan kerusakan jalan yang telah di perhitungkan maka dapat dilihat pada Tabel 2.4 Hubungan Nilai PCl dengan Kondisi Jalan.

\section{HASIL}

Berdasarkan dari hasil penelitian ynang penulis lakukan pada Dusun Batu Alang sampai dengan kampus Universitas Teknologi Sumbawa dengan jarak ukur $2200 \mathrm{~m}$. Pada setiap segmen dengan ukuran $100 \mathrm{~m} /$ segmen.

Ruas jalan Dusun Batu Alang diteliti merupakan jalan lingkungan. Ruas jalan ini merupakan ruas jalan yang memiliki satu jalur untuk dua lajur, dengan lebar perkerasan jalan 3 meter, sedangkan klasifikasi medannya berada di daerah persawahan yang dekat dengan kampus Universitas Teknologi Sumbawa dan ramai penduduk, sehingga sebagian besar badan jalan mengalami kerusakan yang mengakibatkan jalan tersebut kurang maksimal untuk dilewati. Adapun tabel 4.1 Penampang Melintang Jalan yang dapat diketahui: 
Tabel Kriteria Jalan di Lokasi

\begin{tabular}{ll} 
Jenis & Keterangan \\
\hline Tipe Jalan & 1 Jalur, 2 Lajur. \\
$\begin{array}{l}\text { Panjang Segmen } \\
\text { Penelitian } \\
\text { Lebar Jalur }\end{array}$ & 2200 Meter \\
& 2,98 Meter \\
& 3,10 Meter
\end{tabular}

\section{Hasil Analisis}

Dari hasil pengamatan visual dari lapangan diperoleh luas kerusakan, panjang kerusakan, lebar kerusakan, tebal kerusakan, dan kedalaman kerusakan yang nantinya akan menentukan kelas dari berbagai tingkat kerusakan jalan. Densitas kerusakan ini didapat setelah melakukan pengukuran dari tiap jenis kerusakan dan luas kerusakan jalan dari seluruh segmen yang ditinjau. Density dapat segera dihitung.

Penentuan deduct value dapat diperoleh setelah mendapat hasil kelas kerusakan dan density. Setelah itu, $T D V$ dan CDV dapat dihitung setelah mendapatkan hasil density. Setelah mendapatkan nilai - nilai tersebut maka langkah selanjutnya adalah menentukan nilai Pavement Condition Index (PCl). Adapun langkah - langkah perhitungan dengan menggunakan metode $\mathrm{PCl}$ adalah sebagai berikut:

\section{Membuat peta kerusakan jalan}

Peta kerusakan jalan dibuat berdasarkan survey sehingga diperoleh luas, kedalaman ataupun lebar retak yang nantinya dipergunakan untuk menentukan kedalaman ataupun lebar retak yang nantinya dipergunakan untuk menentukan kelas kerusakan.

2. Membuat catatan kondisi dan kerusakan jalan

Catatan kondisi dan kerusakan jalan berupa table yang diisi jenis, dimensi, tingkat, dan lokasi terjadinya kerusakan. Catatan ini merupakan catatan berupa dokumentasi dari kondisi jalan oada masing-masing segmen.

3. Memasukkan nilai-nilai catatan

Kondisi jalan dan hasil dari penelitian kedalam formulir survey untuk dapat diperhitungkan. Sehingga memudahkan penulis untuk menghitung disetiap segmen. Formulir tersebut dapat dilihat dari Tabel 2. Formulir Survei, misalnya pada segmen STA 0+000 sampai dengan STA 0+100 yaitu:

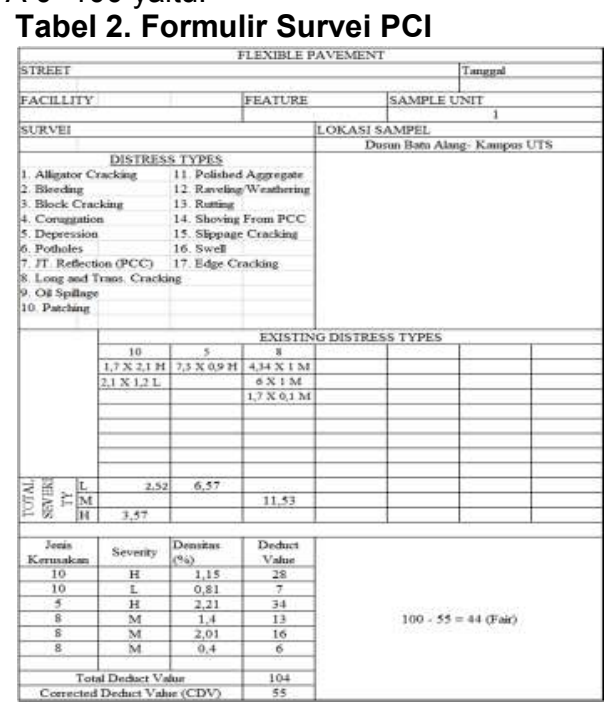

\section{Menentukan nilai pengurangan (deduct value)}

a. Jumlahkan tipe kerusakan pada setiap kerusakan yang terlihat dalam tabel formulir dan catat kerusakan pada kolom "total severity".

b. Menghitung Densitas

$$
\text { Densitas } \frac{\text { Total Densitas }}{\text { Panjang STA } x \text { Lebar STA }} \times 100 \%
$$

c. Hitung pengurang (deduct value) dari tabel grafik-grafik yang sesuai dengan jenis yang dibutuhkan untuk perhitungan $\mathrm{PCl}$ dengan permukaan perkerasan aspal

d. Mencari nilai pengurangan terkoreksi maksumum (CDV)

Corrected Deduct Value dipoleh dari masing-masing kurva hubungan antara TDV dan CDV dengan pemilihan lengkung kurva sesai masing- masing jenis kerusakan jalan sesuai dengan jumlah nilai individual deduct value yang mempunyai nilai lebih dari 5 yaitu disebut dengan nilai Q. sebelum mencari nilai CDV maksimum yang telah dikoreksi, nilai tersebt dapat diperoleh dari nilai yang berdekatan diatas nilai 5 . Misalnya dari segmen $0+000 \mathrm{~s} / \mathrm{d}$ 0+100 terdapat 6 Deduct Value, maka nilai $Q$ yang diperoleh yaitu 6 karena nilai yang lebih dari 5 yaitu 6 . Maka dari grafik CDV yang dapat ddilihat dari Tabel 4.4 Corrected Deduct Value dinilai dengan 55.

e. Menghitung kondisi nilai perkerasan $\mathrm{PCl}$

Nilai kondisi perkerasan dengan mengurangi nilai 100 dan dikurang dengan nilai Corrected Deduct Value (CDV). Nilai PCI $=100-$ CDV

Keterangan:

$\mathrm{PCl}=$ Nilai Kondisi Perkerasan

$\mathrm{CDV} \quad=$ Corrected Deduct Value

Dari perhitungan ini, akan mendapatkan nilai perkerasan pada segmen yang ditinjau. Contoh nilai hitungan $\mathrm{PCl}$ dengan menggunakan CDV STA 0+000 s/d $0+100$ yaitu sebagai berikut:

$\mathrm{PCl}=100-55=45$ (Fair)

Teknik Perbaikan atau Penanganan Kerusakan Jalan

Dalam melakukan penanganan pada tiap segmen kerusakan jalan maka harus sesuai dengan tingkat kerusakan jalan tersebut. Dalam metode PCI ini, memiliki tingkat kerusakan yaitu untuk menjadi acuan penangan kerusakan jalan.

Pemeliharaan jalan merupakan suatu kegiatan yang dilakukan dengan cara pencegahan, perawatan jalan, perawatan jalan, dan perbaikan jalan. Yang dibutuhkan untuk mempertahankan kondisi jalan agar tetap berfungsi secara optimal untuk melayani lalu lintas sampai tercapainya nilai umur rencana yang telah ditetapkan. Untuk penilaian rating memiliki beberapa jenis tingkatan. 0 25 dapat melakukan penanganan rekonstruksi pada kerusakan jalan. 25-60 dapat melakukan penanganan rehabilitas pada kerusakan jalan. 60-80 dapat melakukan penanganan rekronstruksi pada kerusakan jalan. Sedangkan 80-100 dapat melakukan penanganan dengan cara pemeliharaan rutin. Adapun beberapa jenis jalan dengan penanganan yang berbeda-beda yaitu: 
1) Pemeliharaan Rutin

Pemeliharaan rutin merupakan kegiatan merawat serta memperbaiki kerusakan-kerusakan jalan yang terjadi pada ruas-ruas jalan dengan kondisi pelayana yang baik. Pemeliharaan rutin adalah pemeliharaan yang dilakukan sepanjang tahun dan sifatnya sebagai proteksi terhadap kerusakan yang lebih parah.

\section{2) Pemeliharaan Berkala}

Pemeliharaan berkala jalan adalah kegiatan penanganan pencegahan terjadinya kerusakan yang luas dan setiap kerusakan yang tidak diperhitungan dalam desain agar penurunan kondisi jalan dapat dikembalikan pada kondisi jalan yang baik sesuai dengan rencana.pemeliharaan berkala ini dilakukan pada waktu tertentu. Penanganan ini dilakukan pada kondisi jalan yang sudah menurun kualitas berkendaraannya sedangkan dengan upaya pemeliharaan rutin tidak dapat mengembalikan kondisi jalan dapa kondisi mantap. Oleh karena itu secara berkala dilakukan pelapisan ulang lapis permukaan agar jalan kembali pada kondisi mantap.

\section{3) Rehabilitas}

Rehabilitas Jalan adalah kegiatan penanganan pencegahan terjadinya kerusakan yang luas dan setiap kerusakan yang tidak diperhitungkan dalam desain, yang berakibat menurunnya kondisi yang baik pada bagian tempat tertentu dari suatu ruas jalan dengan kondisi rusak ringan, agar penurunan kondisi kemantapan tersebut dapat dikembalikan pada kondisi kemantapan yang sesuai dengan rencana.

\section{Rekonstruksi}

Rekonstruksi adalah penigkatan struktur yang merupakan kegiatan penanganan untuk dapat meningkatkan kemampuan bagian ruas jalan yang dalam kondisi rusak berat agar bagian jalan tersebut mempunyai kondisi mantap kembali sesuai dengan umur rencana yang ditetapkan.

\section{5) Urutan Prioritas}

Berdasarkan hasil penelitian didapat rating Pavement Condition Index pada setiap segmen sehingga dapat ditentukan penentuan urutan ruas jalan yang harus diprioritaskan. Untuk lebih jelasnya dapat dilihat pada tabel 3. Tabel urutan prioritas.

\section{Tabel Urutan Prioritas}

\begin{tabular}{c|c|c|c|} 
No & STA & Rating & Nilai PCI \\
\hline 1 & STA $0+100$ & Fair & 45 \\
\hline 2 & STA $0+200$ & Fair & 53 \\
\hline 3 & STA $0+300$ & Very Good & 74 \\
\hline 4 & STA $0+400$ & Very Poor & 21 \\
\hline 5 & STA $0+500$ & Very Poor & 21 \\
\hline 6 & STA $0+600$ & Very Poor & 21 \\
\hline 7 & STA $0+700$ & Very Poor & 23 \\
\hline 8 & STA $0+800$ & Very Good & 75 \\
\hline 9 & STA $0+900$ & Fair & 44 \\
\hline 10 & STA $1+000$ & Very Good & 84 \\
\hline 11 & STA $1+100$ & Fair & 45 \\
\hline 12 & STA $1+200$ & Excellent & 86 \\
\hline 13 & STA $1+300$ & Good & 58 \\
\hline 14 & STA $1+400$ & Fair & 43 \\
\hline 15 & STA $1+500$ & Fair & 55 \\
\hline 16 & STA $1+600$ & Excellent & 100 \\
\hline 17 & STA $1+700$ & Excellent & 88 \\
\hline 18 & STA $1+800$ & Excellent & 100 \\
\hline 19 & STA $1+900$ & Very Good & 84 \\
\hline 20 & STA $2+000$ & Very Good & 77 \\
\hline 21 & STA $2+100$ & Excellent & 100 \\
\hline 22 & STA $2+200$ & Excellent & 92 \\
\hline
\end{tabular}

\section{HASIL \\ Gambaran Umum Kerusakan Jalan}

Kerusakan jalan disebabkan antara lain karena beban lalu lintas berulang yang berlebih (overload), panas atau suhu udara, air dan hujan, serta mutu awal produk jalan yang jelek. Oleh sebab itu disamping direncanakan secara tepat jalan harus dipelihara dengan baik agar dapat melayani pertumbuhan lali lintas selama umur rencana. Pemeliharaan jalan rutin maupun berkala perlu dilakukan untuk mempertahankan keamanan dan kenyamanan jalan bagi pengguna dan menjaga daya tahan atau keawetan sampai umur rencana. (Suwardi dan Sugiharto, 2004).

Tingkatan kerusakan merupakan jenis kerusakan yang memiliki sifat yang berbeda-beda sehingga berpengaruh dengan parahnya kerusakan jalan tersebut. Penanganan kerusakan jalan diajukan agar jaringan jalan tetap dapat melakukan aktivitas peranan yang baik dengan seharusnya. Berdasarkan perihal tersebut maka dakan dilakukan evaluasi kembaliuntuk mengetahui kondisi jalan yang saat ini. Sehingga mempermudah untuk melakukan mengetahui tingkat kerusakan dan jenis kerusakan yang ada pada setiap segmen, hal itu disebut dengan survey pada kondisi jalan. Pada jalan Dusun Batu Alang sampai dengan kampus Universitas Teknologi Sumbawa, memiliki jenis 6 kerusakan yang ada pada jalan tersebut.

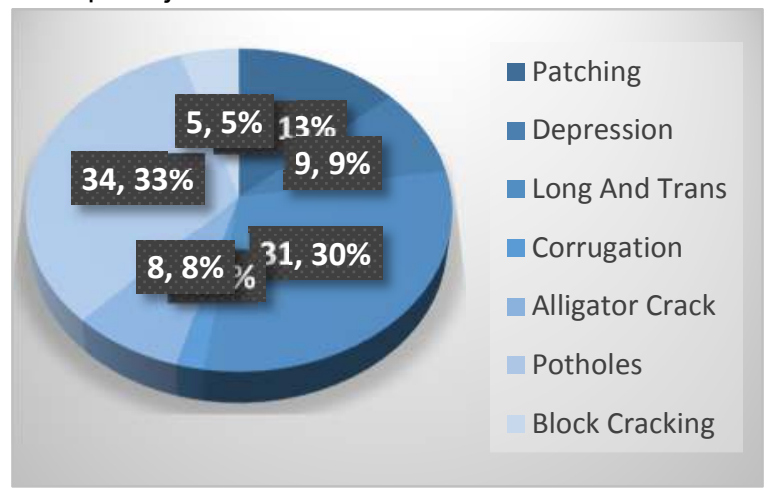

Gambar 4.4 Jenis Kerusakan Pada Jalan Dusun Batu Alang

Pada Gambar 4.4 Jenis Kerusakan Pada Jalan Dusun Batu Alang, dapat diketahui kerusakan jalan di Dusun Batu Alang sampai dengan kampus Universitas Teknologi Sumbawa memiliki beberapa jenis kerusakan yaitu patching yang memiliki $13 \%$ kerusakan, depression memiliki 9\% kerusakan, long and trans. memiliki 30\% kerusakan, corrugation memiliki $2 \%$ kerusakan, alligator cracking memiliki $8 \%$ kerusakan, potholes memiliki 33\% kerusakan, dan block cracking memiliki 5\% kerusakan. Dari banyakanya kerusakan tersebut masing-masing mempunyai tingkat kerusakan yang berbeda.

Jenis-jenis Kerusakan Jalan

Jenis kerusakan jalan pada perkerasan aspal terbagi menjadi dua bagian yaitu:

1) Kerusakan Fungsional merupakan apabila perkerasan tidak dapat berfungsi lagi sesuai yang direncanakan. Kegagalan fungsional pada dasarnya 
tergantung pada derajat atau tingkat kekasaran permukaan.

2) Kerusakan struktural merupakan terjadi ditandai dengan adanya rusak pada satu atau lebih bagian dari struktur perkerasan jalan. Kegagalan struktural disebabkan oleh lapisan tanah dasar yang tidak stabil, beban lalu lintas, kelelahan permukaan, dan pengaruh kondisi lingkungan sekitar.

Berdasarkan penjelasan diatas, dapat disimpulkan pada jalan Dusun Batu Alang sampai dengan kampus Universitas Teknologi Sumbawa dengan jarak $2200 \mathrm{~m}$. dari dua jenis kerusakan diatas pada jalan tersebut lebih banyak memiliki kerusakan struktural. Dikarenakan jenis perkerasan jalan masih dapat menahan beban yang bekerja tetapi tidak adanya tingkat kenyamanan dan keamanan yang diinginkan.

\section{PEMBAHASAN}

\section{Teknik Perbaikan dan Tingkat Kerusakan Jalan}

Dalam melakukan penanganan pada tiap segmen kerusakan jalan maka harus sesuai dengan tingkat kerusakan jalan tersebut. Dalam metode PCI ini, memiliki tingkat kerusakan yaitu untuk menjadi acuan penangan kerusakan jalan.

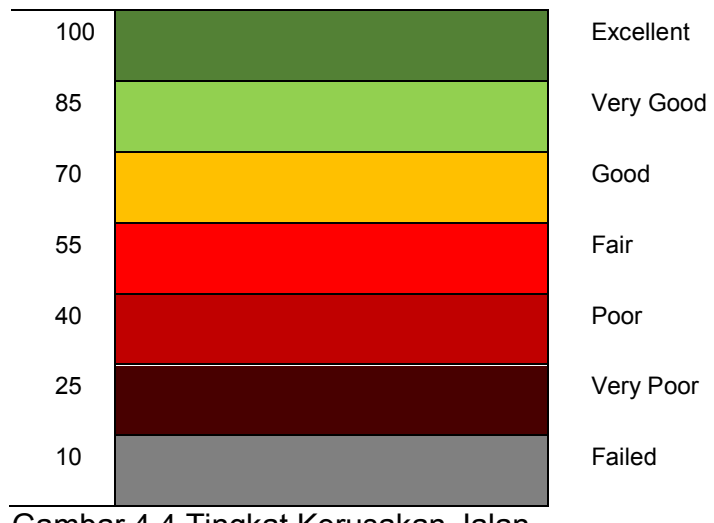

Gambar 4.4 Tingkat Kerusakan Jalan

Pavement Condition Index merupakan metode yang memiliki sistem rating penilaian untuk menyatakan kondisi kerusakan perkerasan jalan yang sesungguhnya. Maka dari itu, ada beberapa tingkat kerusakan jalan yaitu:

\section{1) Excellent}

Excellent merupakan kondisi kerusakan yang masih sempurna dengan nilai rating 100 yang menandakan tidak adanya kerusakan sampai dengan nilai rating 85 yang menandakan kerusakan yang ada pada ruas jalan memiliki kerusakan yang ringan.

\section{2) Very Good}

Very good ialah nilai kerusakan yang menandakan nilai tersebut merupakan nilai yang memiliki tingkat kerusakan ringan sehingga kerusakan tersebut hanya memerlukan tindakan pemeliharaan berkala. Dengan nilai rating 85 sampai dengan 70 .

\section{3) Good}

Good merupakan salah satu jenis tingkat kerusakan perkerasan jalan yang memiliki tingkat kerusakan ringan dan sedang sehingga jenis tingkat kerusakan tersebut memerlukan tindakan pemeliharaan rehabilitas. Dengan nilai rating 70 sampai dengan 55 .

\section{4) Fair}

Fair merupakan salah satu jenis tingkat kerusakan perkerasan jalan yang memiliki tingkat kerusakan sedang sehingga jenis tingkat kerusakan tersebut memerlukan tindakan pemeliharaan rehabilitas. Dengan nilai rating 55 sampai dengan 40 .

\section{5) Poor}

Poor merupakan kondisi kerusakan yang cukup parah sehingga memerlukan pemeliharaan rehabilitas dengan nilai rating 40 sampai dengan nilai rating 25 yang menandakan kerusakan yang ada pada ruas jalan memiliki kerusakan yang sedang.

\section{6) Very Poor}

Very Poor merupakan salah satu jenis tingkat kerusakan perkerasan jalan yang memiliki tingkat kerusakan parah sehingga jenis tingkat kerusakan tersebut memerlukan tindakan pemeliharaan rekonstruksi. Dengan nilai rating 25 sampai dengan 10 .

\section{7) Failed}

Failed merupakan salah satu jenis tingkat kerusakan perkerasan jalan yang memiliki tingkat kerusakan yang sangat parah sehingga jenis tingkat kerusakan tersebut memerlukan tindakan pemeliharaan rekonstruksi. Dengan nilai rating 55 sampai dengan 40 .

Pemeliharaan jalan merupakan suatu kegiatan yang dilakukan dengan cara pencegahan, perawatan jalan, perawatan jalan, dan perbaikan jalan. Yang dibutuhkan untuk mempertahankan kondisi jalan agar tetap berfungsi secara optimal untuk melayani lalu lintas sampai tercapainya nilai umur rencana yang telah ditetapkan. Untuk penilaian rating memiliki beberapa jenis tingkatan. 0-25 dapat melakukan penanganan rekonstruksi pada kerusakan jalan. 25-60 dapat melakukan penanganan rehabilitas pada kerusakan jalan. 60-80 dapat melakukan penanganan pemeliharaan berkala pada kerusakan jalan. Sedangkan 80-100 dapat melakukan penanganan dengan cara pemeliharaan rutin. Adapun beberapa jenis jalan dengan penanganan yang berbeda-beda yaitu:

1) Pemeliharaan Rutin

Pemeliharaan rutin merupakan kegiatan merawat serta memperbaiki kerusakan-kerusakan jalan yang terjadi pada ruas-ruas jalan dengan kondisi pelayana yang baik. Pemeliharaan rutin adalah pemeliharaan yang dilakukan sepanjang tahun dan sifatnya sebagai proteksi terhadap kerusakan yang lebih parah. Adanya jenis kegiatan pemeliharaan jalan rutin yaitu:

- Lapisan permukaan, misalnya pelaburan aspal, penambalan lubang/patching, dan lain-lain.

- Bahu jalan, antara lain pengisian material bahu jalan yang tergerus dan pemotongan rumput.

- Drainase jalan, seperti pembersihan saluran agar tetap berfungsi saat musim hujan. 
Pada Tabel 4.2 Urutan Prioritas menjelaskan beberapa kerusakan yang membutuhkan pemeliharaan rutin berdasarkan pengamatan pada jalan Dusun Batu Alang sampai dengan kampus Universitas teknologi Sumbawa yang panjang jalannya sampai dengan $2200 \mathrm{~m}$ di tiap segmen memiliki $25 \mathrm{~m}$ dengan banyak segmen 88 segmen yang akan dilakukan pemeliharaan rutin. Kerusakan jalan yang membutuhkan pemeliharaan rutin

yaitu ada 30 segmen yaitu:

\begin{tabular}{|l|l|l|}
\hline \multicolumn{3}{|c|}{ Jenis Kerusakan yang membutuhkan Pemeliharaan Rutin } \\
\hline STA $1+000$ & STA $1+200$ & STA $1+700$ \\
\hline STA $1+900$ & STA $2+200$ & \\
\hline
\end{tabular}

\section{2) Pemeliharaan Berkala}

Pemeliharaan berkala jalan adalah kegiatan penanganan pencegahan terjadinya kerusakan yang luas dan setiap kerusakan yang tidak diperhitungan dalam desain agar penurunan kondisi jalan dapat dikembalikan pada kondisi jalan yang baik sesuai dengan rencana.pemeliharaan berkala ini dilakukan pada waktu tertentu. Penanganan ini dilakukan pada kondisi jalan yang sudah menurun kualitas berkendaraannya sedangkan dengan upaya pemeliharaan rutin tidak dapat mengembalikan kondisi jalan dapa kondisi mantap. Oleh karena itu secara berkala dilakukan pelapisan ulang lapis permukaan agar jalan kembali pada kondisi mantap. Pada tabel 4.2 Urutan Prioritas yang menjelaskan kerusakan jalan yang membutuhkan pemeliharaan berkala yaitu pada segmen yang ada dibawah ini. Maka dapat diketahui pada segmen tersebut memerlukan pemeliharaan berkala.

\begin{tabular}{|l|l|l|}
\hline \multicolumn{3}{|c|}{ Kerusakan Jalan Yang Membutuhkan Pemeliharaan Berkala } \\
\hline 1. STA $0+300$ & 2. STA $0+800$ & 3. STA $1+300$ \\
\hline 4. STA $2+000$ & & \\
\hline
\end{tabular}

3) Rehabilitas

Rehabilitas Jalan adalah kegiatan penanganan pencegahan terjadinya kerusakan yang luas dan setiap kerusakan yang tidak diperhitungkan dalam desain, yang berakibat menurunnya kondisi yang baik pada bagian tempat tertentu dari suatu ruas jalan dengan kondisi rusak ringan, agar penurunan kondisi kemantapan tersebut dapat dikembalikan pada kondisi kemantapan yang sesuai dengan rencana.

\begin{tabular}{|c|c|c|}
\hline \multicolumn{3}{|c|}{ Kerusakan Jalan Yang Membutuhkan Rehabilitas } \\
\hline 1. STA $0+100$ & STA $0+200$ & 3. STA $0+900$ \\
\hline 4. STA $1+100$ & STA $1+400$ & b. STA $1+500$ \\
\hline
\end{tabular}

\section{4) Rekonstruksi}

Rekonstruksi adalah penigkatan struktur yang merupakan kegiatan penanganan untuk dapat meningkatkan kemampuan bagian ruas jalan yang dalam kondisi rusak berat agar bagian jalan tersebut mempunyai kondisi mantap kembali sesuai dengan umur rencana yang ditetapkan.

\begin{tabular}{|l|l|c|}
\hline \multicolumn{3}{|c|}{ Kerusakan Jalan Yang Membutuhkan Rekonstruksi } \\
\hline 1. STA 0+500 & 2. STA & 3. STA \\
& $0+600$ & $0+70$ \\
& & 0 \\
\hline
\end{tabular}

\section{PENUTUP}

Berdasarkan hasil penelitian maka nilai rating $\mathrm{PCl}$ dari 22 segmen dengan panjang tiap segmen yaitu $100 \mathrm{~m} /$ segmen terdapat nilai $\mathrm{PCl}$ yang berbeda-beda yaitu untuk segmen $(12,16,17,18$, 21, dan 22) memiliki nilai Excellent. Sedangkan pada segmen $(3,8,10,19$, dan 20$)$ memiliki nilai very good. Selain itu berdasarkan hasil yang sudah dilakukan penelitian, segmen 13 memiliki nilai Good. Adapun yang memerlukan rehabilitas yaitu segmen $(1,2,11,14$, dan 15.) memiliki nilai Fair. Dan segmen yang memiliki nilai very poor yaitu pasa segmen $(4,5,6$ dan 7$)$. Dan dari banyaknya jenis kerusakan jalan hanya ada beberapa kerusakan jalan pada Dusun Batu Alang yaitu Patching, Depression, Long and Trans. Cracking, Corrugation, Alligator Crack, Potholes, Block Cracking.

Dari banyaknya kerusakan tersebut ada beberapa yang memiliki kerusakan yang cukup parah dan ada pula yang memiliki kerusakan yang tidak terlalu parah. Solusi dari beberapa kerusakan tersebut yaitu perbaikan untuk setiap kerusakan yaitu pada segmen $(4,5,6$, dan 7$)$ memerlukan penanganan rekonstruksi. Rekonstruksi dilakukan pada bagian kerusakan jalan yang cukup berat tepatnya pada segmen $(4,5,6$, dan 7$)$ dengan melakukan peningkatan struktural jalan. Kegiatan ini dilakukan dengan cara pelapisan ulang (seal coat) dengan ketebalan yang diizinkan. Kemudian pada segmen $(3,8.13$, dan 20) memerlukan penanganan berkala dengan kegiatan yang dilakukan yaitu penambahan lapisan tipis aspal termasuk diantaranya adalah fog seal, chip seal, micro seal, dan SAMI. Untuk segmen $(10,12,17$, dan segmen 22$)$ memerlukan jenis pemeliharaan rutin, kegiatan yang dilakukan yaitu pemeliharaan/pembersihan rumaja, pemeliharaan sistem drainase, pengisian celah/tanaman liar di rumaja, dan penambalan lubang dan pemeliharaan bangunan pelengkap. Selain itu, pada segmen $(1,2,9,11,14$, dan segmen 15) dilakukan pemeliharaan rehabilitasi, kegiatan ini merupakan kegiatan yang akan dilakukan pada perbaikan bahu jalan, pelepasan ulang, pengasaran permukaan, dan pengisian celah/retak permukaan. Dari keseluruhan unit sempel yang diteliti pada Dusun Batu Alang sebanyak 22 segmen.

\section{Saran}

Dari hasil penelitian ini, kesimpulan dan pembahasan dapat ditarik beberapa saran untuk meningkat kinerja ruas jalan Dusun Batu Alang sampai dengan Universitas Teknologi Sumbawa.

1. Apabila akan dilakukan perbaikan pada kerusakan-kerusakan jalan tersebut, 
sebaiknya terlebih dahulu dilakukan observasi langsung dilapangan oleh pihak terkait, agar perbaikan sesuai dengan kondisi kerusakan yang terjadi, sehingga perbaikan yang dilakukan akan lebih efektif dan efesien.

2. Untuk mempertahankan kinerja perkerasan, diperlukan beberapa tindakan perbaikan kerusakan, baik berupa pemeliharaan rutin yang dilakukan setiap tahun maupun pemeliharaan berkala yang biasanya dilakukan setiap 2 atau 3 tahun sekali.

3. Diharapkan penelitian ini dapat memberikan wawasan bagi pembaca tentang penilaian kondisi kerusakan jalan dengan menggunakan metode Pavement Condition Index.

\section{UCAPAN TERIMAKASIH}

Terselesaikan skripsi ini tidak terlepas dari bantuan banyak pihak, sehingga pada kesempatan ini dengan segala kerendahan hati dan penuh rasa hormat penulis mengucapkan terimakasih yang sebesar-besarnya bagi semua pihak yang telah memberikan bimbingan, dorongan, serta semangat sehingga penulis dapat menyelesaikan tugas akhir ini, terutama kepada yang penulis hormati:

1. Bapak. Mietra Anggara, S.T., M.T. selaku Dekan Fakultas Teknik Universitas Teknologi Sumbawa.

2. Ibu Eti Kurniati S.T., M.T., selaku Ketua Program Studi Teknik Sipil Universitas Teknologi Sumbawa sekaligus Pembimbing II yang selalu memberikan dukungan dan nasehat kepada penulis dalam menyusun skripsi ini

3. Bapak Hermansyah S.T., M.Sc., selaku Dosen Pembimbing I yang juga telah memberikan dukungan dan bimbingan kepada penulis dalam menyempurnakan skripsi ini.

4. Kedua orang tua, ayahanda Abdul Rachman dan ibunda Evi Ririn Yulianti yang senantiasa memberikan dukungan kepada penulis.

5. Kepada teman-teman teknik sipil 2015 yang telah menemani saya selama perkuliahan dalam waktu 4 tahun ini.

6. Bapak/lbu dosen staff di lingkungan Fakultas Teknik Universitas Teknologi Sumbawa, Khususnya Program Studi Teknik Sipil yang Telah membantu agar penulisan Tugas Akhir ini dapat terselesaikan.

Akhir kata penulis mengucapkan terimakasih kepada semua pihak yang telah membantu dan penulis berharap semoga skripsi ini dapat bermanfaat bagi kita semua dan menjadi bahan masukan dalam dunia pendidikan.

\section{DAFTAR PUSTAKA}

Bella, M. E. (2012). Perbandingan Metode Bina Marga Dan Matode PCl (Pavement Condition Index) Perkerasan Jalan. Malang: Universitas Nusa Cendana.

Nugraheni, N. A. (2018). Analisis Kondisi Fungsional Jalan Dengan Metode PSI dan RCI serta Prediksi Sisa Umur Perkerasan Jalan. Surakarta: Matriks Teknik Sipil.
Shahin. (1994). Pavement Maintenance Management for Roads and Streets Using The Paver System. New York: US Army Corps of Engineer.

Sirait, R. B., Syafaruddin A.S, \& Sulandari, E. (2017). Analisa Kondisi Kerusakan Jalan Raya Pada Lapisan Permukaan. Kalimantan Barat: Universitas Tanjungpura.

Widana Putra, I. B. (2009). Kerusakan Jalan Pada Perkerasan Jalan. Depok: Universitas Gunadarma.

Yunardhi, H., Alkasl, M., \& Sutanto, H. (2018). Analisa Kerusakan Jalan Dengan Metode PCl dan Alternatif Penyelesaiannya. Samarinda: Universitas Mulawarman. 